\title{
Acute physical exercise increases the adaptor protein APPL1 in the hypothalamus of obese mice
}

\author{
Rafael Calais Gaspar ${ }^{\mathrm{a}}$, Vitor Rosetto Muñoz ${ }^{\mathrm{a}}$, Guilherme Pedron Formigari ${ }^{\mathrm{b}}$, Gabriel Keine Kuga ${ }^{\mathrm{c}}$, \\ Susana Castelo Branco Ramos Nakandakari ${ }^{\mathrm{b}}$, José Diego Botezelli ${ }^{\mathrm{a}}$, Adelino S.R. da Silva ${ }^{\mathrm{d}}$, \\ Dennys Esper Cintra ${ }^{\mathrm{b}, \mathrm{e}}$, Leandro Pereira de Moura ${ }^{\mathrm{a}, \mathrm{c}, \mathrm{e}, \mathrm{f}}$, Eduardo Rochete Ropelle $^{\mathrm{a}, \mathrm{e}, \mathrm{f}}$, \\ José Rodrigo Pauli ${ }^{\mathrm{a}, \mathrm{e}, \mathrm{f}, *}$ \\ a Laboratory of Molecular Biology of Exercise (LaBMEx), University of Campinas (UNICAMP), Limeira, São Paulo, Brazil \\ ${ }^{\mathrm{b}}$ Laboratory of Nutritional Genomics (LabGeN), University of Campinas (UNICAMP), Limeira, São Paulo, Brazil \\ ${ }^{c}$ Post-graduate Program in Movement Sciences, São Paulo State University (UNESP), Rio Claro, São Paulo, Brazil \\ d Post-graduate Program in Rehabilitation and Functional Performance, Ribeirão Preto Medical School, USP, Ribeirão Preto, São Paulo, Brazil \\ ${ }^{\mathrm{e}}$ Laboratory of Cell Signaling, Obesity and Comorbidities Research Center (OCRC), University of Campinas, Campinas, SP, Brazil \\ ${ }^{\mathrm{f}}$ CEPECE - Center of Research in Sport Sciences, School of Applied Sciences, University of Campinas (UNICAMP), Limeira, São Paulo 13484-350, Brazil
}

\section{A R T I C L E I N F O}

\section{Keywords:}

Obesity

Physical exercise

Adiponectin

Hypothalamus

APPL1

\begin{abstract}
A B S T R A C T
Adiponectin is considered an adipokine that has essential anti-inflammatory and insulin-sensitivity actions. The adaptor protein containing the pleckstrin homology domain, the phosphotyrosine-binding domain, and leucine zipper motif 1 (APPL1) is a protein involved in adiponectin signaling that plays a role in many physiological and pathophysiological processes. In the central nervous system, adiponectin can potentiate the effects of leptin in the arcuate proopiomelanocortin (POMC) neurons. However, the role of APPL1 in the hypothalamus is not well understood. Therefore, in this study, we explored the effects of acute physical exercise on APPL1 protein content in the hypothalamus and food intake control in leptin stimulated-obese mice. Here we show that acute exercise increased serum adiponectin levels and APPL1 content in the hypothalamus, which were followed by reduced food intake in obese mice. Further, at the molecular level, the exercised obese mice increased the protein kinase B (Akt) signaling in the hypothalamus and attenuated the mammalian homolog of Drosophila tribbles protein 3 (TRB3) levels. In conclusion, the results indicate physical exercise is capable of increasing APPL1 protein content in the hypothalamus of leptin stimulated-obese mice and modulating food intake.
\end{abstract}

\section{Introduction}

Obesity is a disease characterized by abnormal or excessive body fat accumulation and has a worldwide prevalence [1]. Acquired adiposity is the consequence of a chronic positive energy balance, which the hypothalamus plays a crucial role. The hypothalamus receives peripheral stimuli during the food intake and thermogenesis regulation [2]. Among these stimuli, we can highlight the action of adipokines and hormones (adiponectin and leptin) for adequate energy metabolism regulation $[2,3]$.

Adiponectin performs important peripheral roles such as insulinsensitivity, anti-inflammatory properties, participation in fat oxidation, and glucose metabolism [4,5]. It is known that APPL1 is the most important protein in the adiponectin signaling pathway [5]. When associated with adiponectin receptors (AdipoRs), APPL1 becomes active and mediates the intracellular signaling of adiponectin [6]. Despite its relevant peripheral role, the central actions of this adipokine are not completely clear in the literature. Recently, at the central level, it was observed that adiponectin could potentiate the effects of leptin in the arcuate POMC neurons [7]. However, the role of APPL1 in this mechanism was not reported. The APPL1 was able to mediate leptin signaling in hepatocellular carcinoma HepG2 cell and breast cancer MCF-7 cell [8]. Furthermore, it was shown that APPL1 can bind to the leptin receptor (LepR) and to signal transducer and activator of transcription 3 (STAT3) [8]. However, the molecular mechanism responsible for controlling the central actions of adiponectin is not known. Thus, we hypothesize that APPL1 may be a crucial protein in the food intake control by leptin stimulus.

APPL1 is a protein highly conserved in different species and expressed in several tissues such as heart, brain, and skeletal muscle. This

\footnotetext{
* Corresponding author at: 1300 Pedro Zaccaria St. 1068, Jd. Sta. Luzia, CEP 13484-350, Limeira, São Paulo, Brazil.

E-mail address: jose.pauli@fca.unicamp.br (J.R. Pauli).
} 
protein has a PTB (phosphotyrosine-binding) domain, which is an essential molecule in insulin sensitivity [6]. In fact, APPL1 can associate with substrates of insulin receptor 1 and 2 (IRS-1 and IRS-2), Akt, and the P110 subunit of the phosphoinositide 3-kinase (PI3K) protein, which improves insulin sensitivity [9-11]. Also, APPL1 can prevent Akt from being inactivated by the TRB3 protein [12]. Furthermore, obesity is associated with a reduction in serum adiponectin levels, in the AdipoR1 (adiponectin 1 receptor) as well as in the APPL1 protein content in peripheral tissues [13-15]. On the other hand, APPL isoform 2 (APPL2) performs a counteraction in APPL1 regulation [6]. The overexpression of APPL2 in C2C12 cells results in the adiponectin pathway negative regulation and lower APPL1 activation [16]. Also, in humans, weight excess and obesity are correlated with polymorphisms in the APPL2 gene [17].

Physical exercise has been recommended as an important nonpharmacological strategy to treat and prevent obesity [18]. Studies have shown that exercised obese rodents presented an increase in AdipoR1, AdipoR2, and APPL1 protein contents in the liver, skeletal muscle, and white adipose tissue (WAT), which can restore glycemic homeostasis $[13,19]$. However, Coope and colleagues showed that AdipoR1 mediates the anorectic and insulin/leptin-like actions of adiponectin in the hypothalamus of Wistar rats [2]. In parallel, a previous study indicated other central effects of adiponectin on energy balance by regulating locomotor activity in rats [3]. Therefore, the molecular pathway underlying the anorectic effect of adiponectin is not yet fully elucidated.

Although the role of adiponectin in the central nervous system (CNS) has been previously explored [2,3], the effects of obesity and exercise on hypothalamic APPL1 protein levels are not known. Here we hypothesized that APPL1 might be crucial in the control of food intake. Thus, this study aimed to investigate the effects of an acute physical exercise session on hypothalamic APPL1 protein content and food intake control in obese mice induced by a high-fat diet.

\section{Experimental procedures}

\subsection{Experimental animals}

Four-week-old Swiss mice were used from the Multidisciplinary Center for Biological Investigation on Laboratory Animal Science (CEMIB) - University of Campinas (UNICAMP). All experiments were approved by the Ethics Committee in the use of Animal (CEUA) of the Institute of Biological Sciences, UNICAMP - Campinas-SP, protocol no. 3946-1.

After six weeks of age, the mice were divided into two groups: Control Group $(\mathrm{CTL})=$ mice fed with a commercial diet $\left(\right.$ NUVILAB $\left.^{\circledR}\right)$ and Obese group $(\mathrm{OB})=$ mice fed with a high-fat diet. The high-fat diet was modified to contain approximately $35 \%$ of lipids $(31.2 \%$ of lard and $4.0 \%$ of soybean oil), and the diet composition was the same as previously described [Control Diet: $42.75 \%$ Corn Starch, 20\% Casein, 13.2\% Sucrose, 10\% Dextrinated Starch, 4\% Soybean Oil, 5\% Cellulose, 3.5\% Mineral Mix, 1\% Vitamin Mix, 0.3\% L-Cysteine, 0.25\% Choline; High-Fat Diet: $11.55 \%$ Corn Starch, 20\% Casein, 13.2\% Sucrose, 10\% Dextrinated Starch, 4\% Soybean Oil, 31.2\% Lard, 5\% Cellulose, 3.5\% Mineral Mix, 1\% Vitamin Mix, 0.3\% L-Cysteine, 0.25\% Choline] $[20,21]$. This intervention lasted eight weeks until the mice become glucose intolerant. Further, the OB group was distributed in the following subgroups: High-fat Diet (HFD) = animals fed with a high-fat diet and not submitted to the physical exercise protocol; High-fat Diet Exercised (HFD-EXE): animals fed with a high-fat diet and submitted to

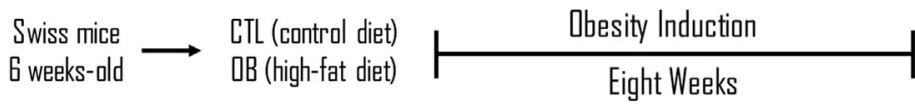

an acute exercise protocol (Fig. 1A). Body mass was analyzed in the beginning and at the end of the experimental period using the Gehaka ${ }^{\circledR}$ analytical balance (BK3000).

\subsection{Treadmill adaptation and incremental load test}

The animals were adapted to the treadmill to minimize their stress during the incremental load test and acute exercise session. The animals were adapted for 5 days, $10 \mathrm{~min} /$ day at a speed of $3 \mathrm{~m} / \mathrm{min}$, as previously standardized [22]. The incremental load test was performed two days after the adaptation period. The initial velocity of the test was $6 \mathrm{~m} / \mathrm{min}$, with $0 \%$ of inclination and increments of $3 \mathrm{~m} / \mathrm{min}$ every 3 min until exhaustion, which occurred when the mice touched five times the end of the treadmill without an interval of $1 \mathrm{~min}$. The velocity $(\mathrm{m} / \mathrm{min}$ ) of exhaustion (EV) was used to prescribe the intensity of the acute exercise session. After two days of the incremental load test, the acute physical exercise protocol was performed.

\subsection{Acute aerobic physical exercise protocol}

The acute aerobic physical exercise protocol consisted of a single session of treadmill running exercise without inclination. The mice ran three bouts of $45 \mathrm{~min}$ with $15 \mathrm{~min}$ of passive recovery between them, totalizing $2 \mathrm{~h}$ and $45 \mathrm{~min}$ for the total protocol. The intensity used was $60 \%$ of the EV (Fig. 2). For the physiological analysis and tissue extraction, the animals remained eight hours fasting. The HFD-EXE group started the fasting concomitant to the physical exercise protocol.

\subsection{Glucose tolerance test (GTT)}

After $8 \mathrm{~h}$ fasting, it was performed a distal puncture in the tail of the animals for basal glucose analysis, equivalent to time zero (t0) in the protocol. An intraperitoneal (IP) injection of glucose solution [50\%] in a dose of $2 \mathrm{~g} / \mathrm{kg}$ body weight was applied. Subsequently, blood samples were collected at 30,60 and $120 \mathrm{~min}$ for serum glucose levels. Then, the area under the curve was calculated for each experimental group.

\subsection{Evaluation of food intake}

Firstly, the food intake was determined to measure the difference between the weight of the diet offered to the animal and the weight of the remaining diet after $24 \mathrm{~h}$ (6:00 p.m. to 6:00 p.m.). This procedure was performed with the animals in individual cages without previously fasting period. This procedure was performed again after $24 \mathrm{~h}$ of the exercise protocol (6:00 p.m. to 6:00 p.m.). In this second analysis, there was a previous 8-hour fasting period for all experimental groups (Fig. 4A), which was adopted to match with the fasting period and time after the exercise that was utilized for the euthanasia of the animals, in which the hypothalamus was extracted for molecular analysis. The weight measurement was accessed by Gehaka $^{\circledR}$ analytical balance (BK3000).

\subsection{Serum adiponectin concentration}

Before the tissue extraction, the blood was collected from the tail, centrifuged (Eppendorf ${ }^{\circledR}$ Centrifuge $5804 \mathrm{R}$ ) at $3500 \mathrm{rpm}$ during $15 \mathrm{~min}$ and the serum stored at $-80^{\circ} \mathrm{C}$. Subsequently, the concentrations of adiponectin were determined by the enzyme immunoassay (ELISA) method using the commercial kit (Mouse Adiponectin/Acrp30 R \& D

Systems ${ }^{\circledR}$ - \#DY1119)

CTL (control diet) $\mathrm{DB}$ (high-fat diet)

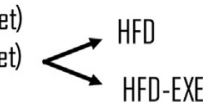

Fig. 1. Experimental design. The Swiss mice were divided into two groups: control (CTL), fed a chow diet; and obese (OB), fed a highfat diet for eight weeks. After obesity in-

duction, the OB animals were divided into two subgroups: HFD and HFD-EXE. 


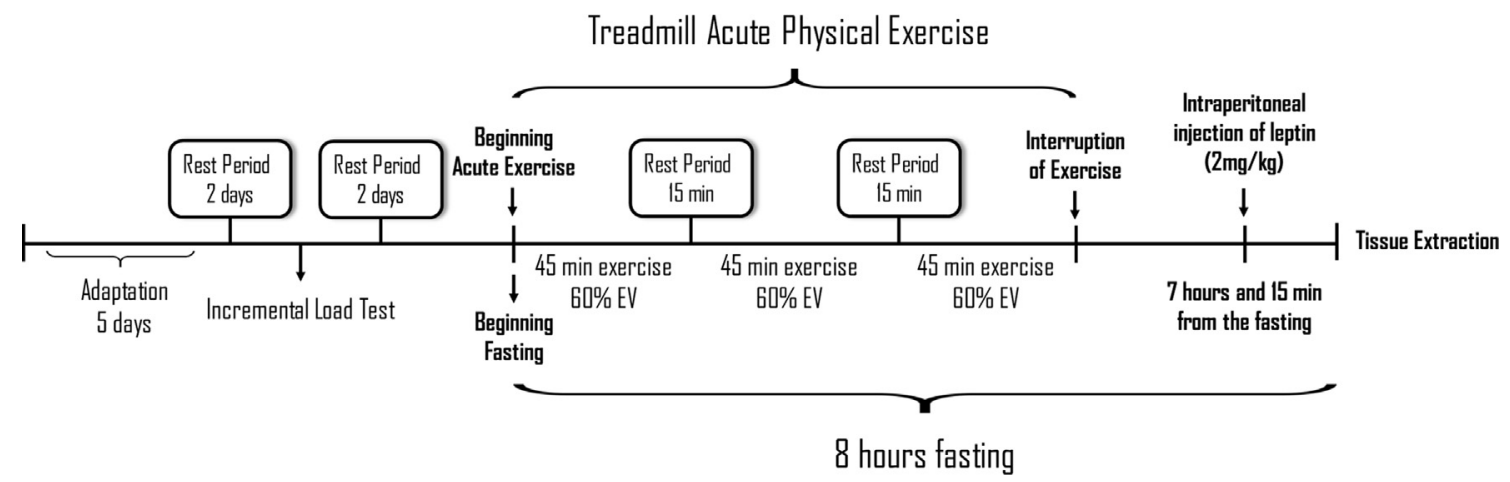

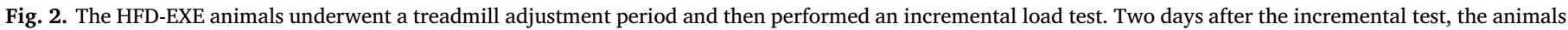
were submitted to the acute physical exercise protocol, which consisted of three 45 min exercise sessions with 15 min intervals between each session.

\subsection{Leptin administration}

After $4 \mathrm{~h}$ and $30 \mathrm{~min}$ from the exercise protocol or $7 \mathrm{~h}$ and $15 \mathrm{~min}$ from the fasting (CTL and HFD group), the animals received an intraperitoneal injection of leptin (BioVision ${ }^{\circledast}$ \#4367) $(2 \mathrm{mg} / \mathrm{kg}$ ), and 45 min later the animals were sacrificed (Fig. 2). Adapted from Patterson et al. [23].

\subsection{Tissue extraction and blood collection}

After the physical exercise protocol and intraperitoneal leptin stimulation, which were previously described, the animals were euthanized (Fig. 2). Hypothalamus and white adipose tissue were extracted. The hypothalamus was homogenized in extraction buffer according to the previous investigation of our research group [24]. Part of the homogenate was used for determination of the total protein content by the Bicinchoninic Acid (BCA) method (Sigma-Aldrich ${ }^{\circledast}$ ), while another part was subjected to western blotting (WB) with specific antibodies. The adipose mass was collected and weighed on the Gehaka $^{\circledR}$ analytical balance (BK3000).

\subsection{Western blotting (WB)}

After determination of the total protein content, Laemmli buffer containing $100 \mathrm{mM}$ DTT was added to the supernatant and heated during $5 \mathrm{~min}$ [25]. Equal amounts of protein $(70 \mu \mathrm{g} / \mu \mathrm{L})$ were subjected to SDS-PAGE polyacrylamide gel electrophores. Ponceau staining was applied to check membrane transfer. Then, the membranes were incubated overnight at $4{ }^{\circ} \mathrm{C}$ with the following primary antibodies (dilution 1:1000 $\mu \mathrm{L}$ ): Cell Signaling Technology: $\beta$-Actin [rabbit, 4967s]. Santa Cruz Biotechnology: AdipoR1 [goat, sc-46748], APPL1 [rabbit, sc-67402], p-Akt 1/2/3 (ser 473) [rabbit, sc-33437], Akt 1/2/3 [rabbit, sc-8312], and TRB3 [rabbit, sc-67122]. Novus Biologicals: DIP13B (APPL2) [rabbit, NBP2-16165]. Next, the membranes were incubated for $1 \mathrm{~h}$ with the specific secondary antibodies (dilution 1:2000 $\mu \mathrm{L}$; Antirabbit IgG, HRP-linked Antibody [Cell Signaling Technology \#7074]; donkey anti-goat IgG-FITC sc-2024 [Santa Cruz Biotechnology]), and the bands were visualized with enhanced chemiluminescence (ECL) and quantified by densitometry. Proteins were normalized by $\beta$-actin and $\mathrm{p}$ Akt normalized by total Akt.

\subsection{Statistical analysis}

All results are expressed as mean \pm S.D. The Western blotting results are presented and quantified by densitometry using the Un-Scan-It Gel $6.1^{\circledast}$ program and normalized by respective endogen control. Firstly, to access the normality of the data, Shapiro-Wilk W-test was used. For normally distributed data, Analysis of Variance (ANOVA), followed by the Tukey's post-hoc test, was used. To the data without normal distribution, a non-parametric test (Kruskal-Wallis test) was used. For the correlation analysis, we performed the Pearson's correlations test. The statistical significance was set at $\mathrm{p}<0.05$ as statistically significant, $\mathrm{p}<0.01$ as very significant and $\mathrm{p}<0.001$ as very extremely. The program "GraphPad Prism 6.02" was used.

\section{Results}

3.1. Acute physical exercise decreases glucose intolerance and restores serum adiponectin in obese mice independent of fat mass

Firstly, we found the physical exercise session protected against glucose intolerance and increased serum adiponectin, concomitantly. Thus, after obesity induction, the animals showed increased body weight and fat mass (Fig. 3A-D). The HFD group showed higher glucose intolerance compared to the CTL group (Fig. 3E-G). On the other hand, the HFD-EXE animals presented reduced fasting glucose and glucose intolerance compared to the HFD group (Fig. 3E-G), which can confirm the positive effects of physical exercise. Interestingly, serum adiponectin levels were reduced in the HFD animals compared to the CTL animals, but the physical exercise session restored the serum concentration of this adipokine (Fig. 3H). These results occurred with no alterations in body weight (Fig. 3A-D).

\subsection{Acute physical exercise increased hypothalamic APPL1 protein content}

Once verified the physiologic effects of physical exercise, we analyzed the positive effects of this intervention in modulating the adiponectin pathway (Fig. 4A). We observed that the HFD animals reduced the APPL1 protein content. When submitted to physical exercise, the HFD-EXE group's hypothalamic APPL1 content was restored (Fig. 4C). Also, no significant differences in AdipoR1 (Fig. 4B) and APPL2 (Fig. 4C) contents were observed between the sedentary and exercised obese animals.

\subsection{Exercise increased Akt phosphorylation}

Since APPL1 is crucial for Akt action through competition with TRB3 protein [26], we verified if the exercise increased p-Akt (Fig. 5A). Thus, the HFD group presented a natural increase of $59 \%$ of TRB3 content protein, which was not significant. However, physical exercise attenuates such changes (Fig. 5B). Additionally, we identified that, after the acute physical exercise protocol, the HFD-EXE animals presented a higher Akt phosphorylation compared to the HFD animals (Fig. 5C). Furthermore, we did not observe a difference in the TRB3/APPL1 correlation (Fig. 5D). Also, the Fig. 5E shows a strong positive correlation between the levels of APPL1 and p-Akt $(r=0.7502)$. 
A. Initial Body Weight

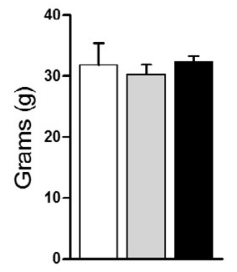

B.

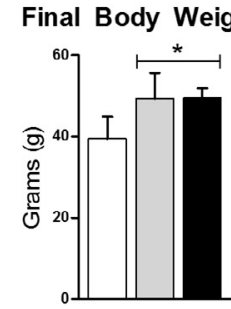

C

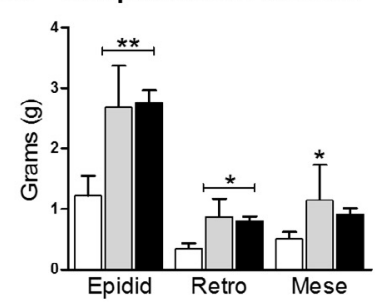

E.

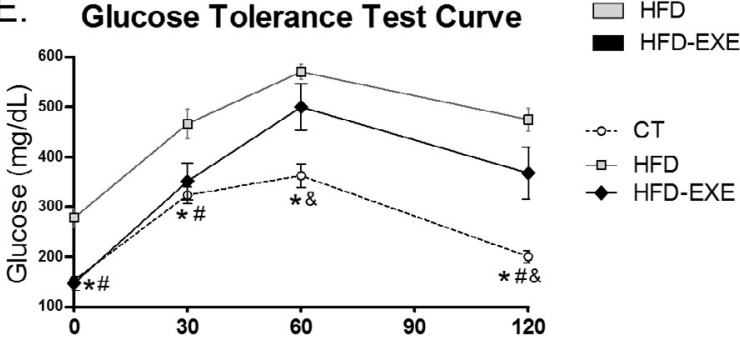

F.

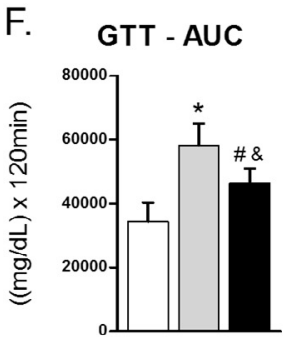

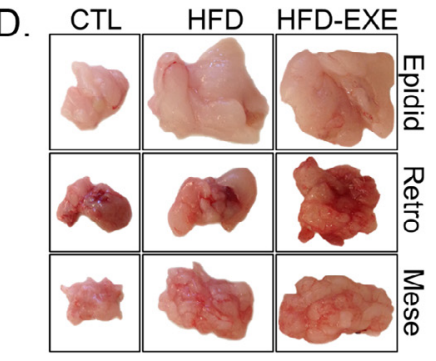

G.

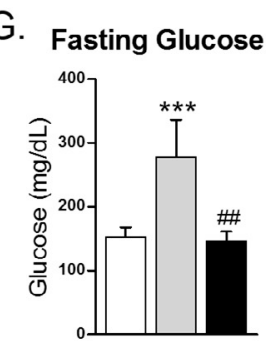

$\mathrm{H}$.

Serum Adiponectin

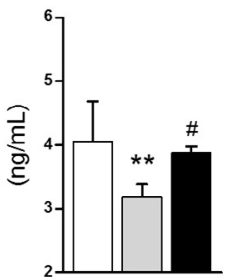

Fig. 3. The Swiss mice were divided into three groups: Control (CTL) $n=10$, high-fat diet (HFD) $n=10$, and high-fat Diet Exercised (HFD-EXE) $n=10$. (A) Initial body mass. (B) Body mass after dietary intervention. (C) Intraperitoneal fat mass at the end of the experimental protocol. (D) Representative image from different adipose tissue (Epididymal, retroperitoneal, and mesenteric). (E) The glucose tolerance test curve was performed, (F) the area under the curve was calculated for each experimental group, and (G) fasting glucose evaluated at the first point of GTT. (H) Finally, the analysis of serum adiponectin was performed. The bar charts represent the means and standard deviation $( \pm$ ) of each experimental group. " $p<0.05$ HFD vs CTL, \#p $<0.05$ HFD-EXE vs HFD, and \&p $<0.05$ HFD-EXE vs CTL. One-way ANOVA was performed to compare the control and experimental groups and Two-way ANOVA was used in the glucose tolerance test curve to repeat the measures of each point. One signal: $\mathrm{p}<0.05$ statistically significant. Two signals: $\mathrm{p}<0.01$ very significant. Three signals: $\mathrm{p}<0.001$ extreme power.

\subsection{Food intake after acute physical exercise}

After verifying the molecular effects in the hypothalamus of the HFD-EXE animals, we used another cohort of animals to evaluate the food intake. Thus, the exercised animals reduced hyperphagia (Fig. 6A). We observed a lower caloric intake in the CTL group compared to the HFD and HFD-EXE groups before the exercise session (Fig. 6B). It is important to highlight that none of the groups were previously fasting. However, $24 \mathrm{~h}$ after the acute exercise, the HFD-EXE group presented a significant reduction in the food intake compared to the HFD group (Fig. 6C). After that, we verified that the protein content of APPL1 was negatively correlated $(r=-0.6305)$ with food intake after exercise (Fig. 6D).

\section{Discussion}

Adiponectin has been a target of interest for the scientific community because it promotes beneficial effects on the insulin and leptinsignaling pathway. Our results confirmed that there are physiological disorders involved in obesity such as decreased serum adiponectin, increased fasting blood glucose, and glucose intolerance. Moreover, we found that obesity is linked to hyperphagic behavior and reduced APPL1 hypothalamic levels. This study is the first one showing that exercise regulates the APPL1 protein content in the hypothalamus.

There is a growing amount of evidence supporting the role of physical exercise promoting benefits to CNS and food intake control. Previous studies have shown the role of physical exercise modulating the APPL1 content in peripheral tissues such as liver and skeletal muscle positively $[13,19]$. Also, APPL1 hepatic suppression resulted in both damage to insulin sensitivity and increased hepatic glucose production [12]. The same author also demonstrated the overexpression of APPL1 reestablished glucose homeostasis, which increased insulin sensitivity and reduced gluconeogenesis [12]. Interestingly, in our study, acute physical exercise increased the hypothalamic APPL1 content and consequently decreased the food intake.

Recently, it was demonstrated that the adipokine resistin could decrease adiponectin signaling in the hypothalamus of Wistar rats [9]. Resistin is directly associated with insulin resistance and type 2
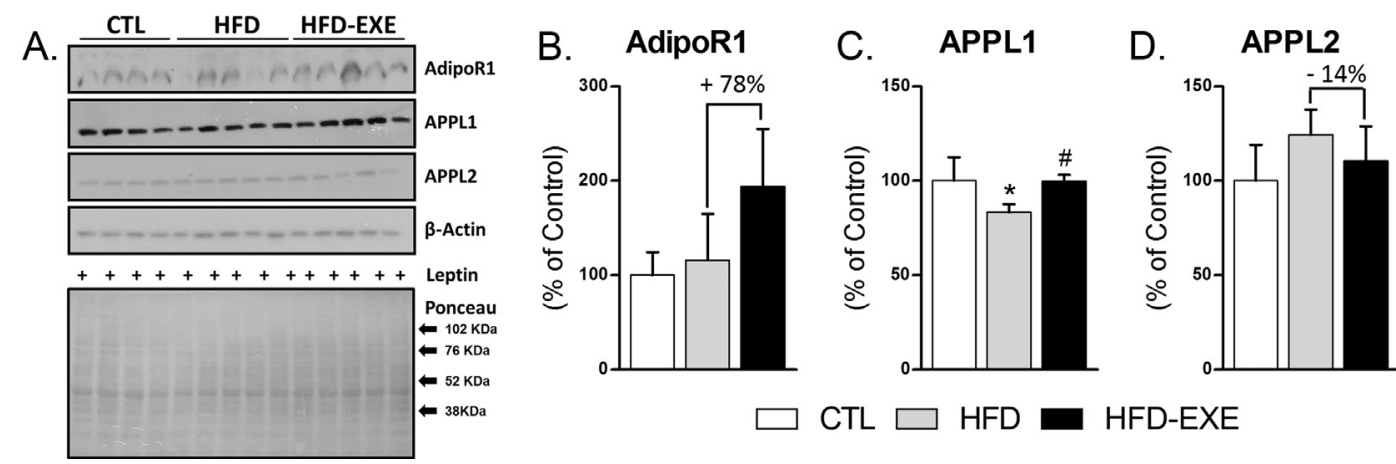

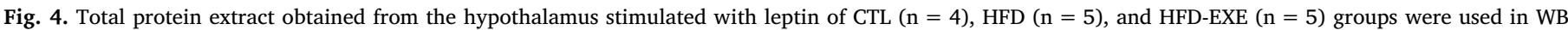

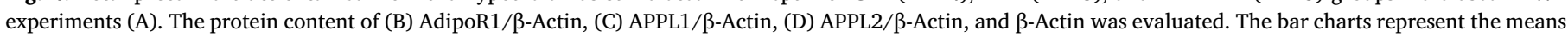

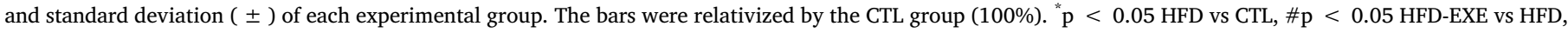
and \&p $<0.05$ HFD-EXE vs CTL. One-way ANOVA was performed to compare the control and experimental groups. 


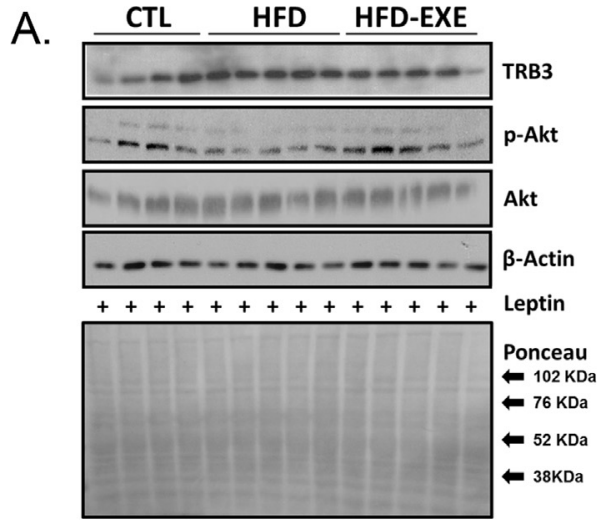

D.

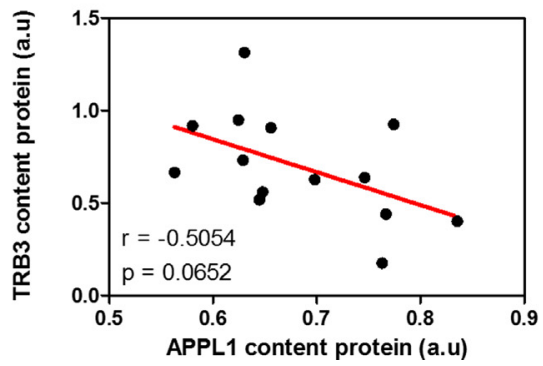

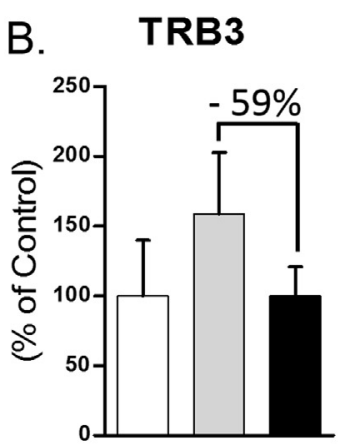

C. p-Akt

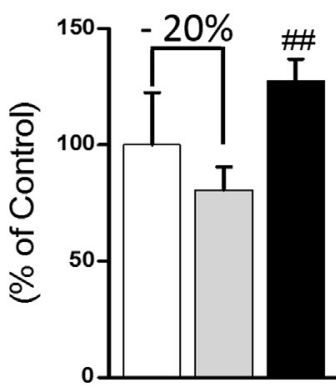

CTL $\square$ HFD $\square$ HFD-EXE

E.

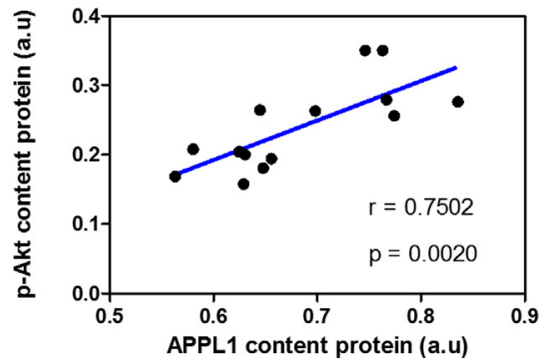

Fig. 5. Total protein extract obtained from the hypothalamus stimulated with leptin of the animals from the CTL ( $n=4)$, HFD $(n=5)$, and HFD-EXE ( $n=5$ ) groups were used in Western Blotting (WB) experiments (A). The protein content of (B) TRB3/B-Actin and (C) p-Akt/Akt. The bars were relativized by the CTL group (100\%). $\# \mathrm{p}<0.05$ HFD-EXE vs. HFD. One-way ANOVA was performed to compare the control and experimental groups.

diabetes (DM2) in rodents $[27,28]$. At the central level, resistin can modulate food intake of rats [29]. Thus, it was observed the ICV injection of resistin resulted in a reduction in mRNA levels of AdipoR1, AdipoR2, and APPL1. Also, the stimulus resulted in a decrease in hypothalamic APPL1/Akt association and increased the TRB3/Akt association [9]. Therefore, this may be a possible mechanism explaining the reduction of the levels of APPL1 in the present study.

On the other hand, our research group demonstrated that physical exercise could modulate the TRB3/Akt interaction in the periphery and CNS $[19,30]$. Thus, Rodrigues et al. verified acute physical exercise was able to reduce the TRB3 protein content, increase the Akt phosphorylation, and reduce the TRB3/Akt interaction in the hypothalamus of obese rats, restoring energy homeostasis [30]. Besides the difference between the species of rodents used in those studies (Wistar rats and Swiss mice) and the kind of exercise protocol, these findings strengthen the results of the present investigation. Rodrigues and colleagues used the swimming exercise protocol of $6 \mathrm{~h}$ and $45 \mathrm{~min}$ [30]. We performed treadmill exercise with $2 \mathrm{~h}$ and $45 \mathrm{~min}$ of volume. These differences may explain the small variations in both studies. However, based on the lack of TRB3 modulation and the high positive correlation between APPL1 protein content and p-Akt, we can suggest that the increased APPL1 in the hypothalamus of obese animals is increasing the Akt protein activity.

The central action of adiponectin in the control of food intake is

A.

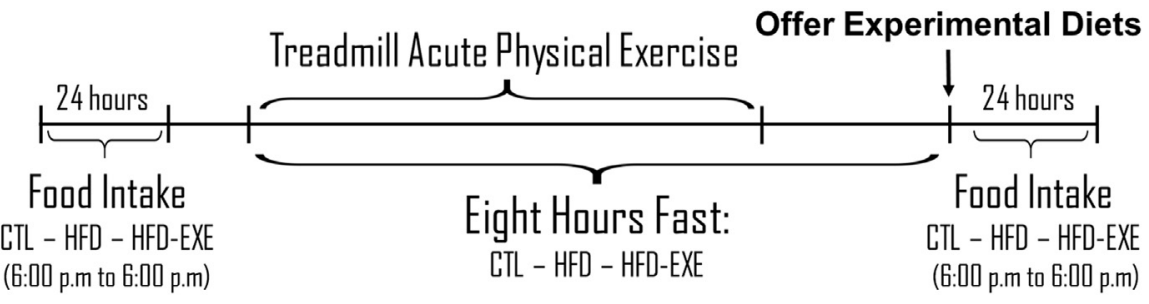

B. 24h Food Intake before Exercise

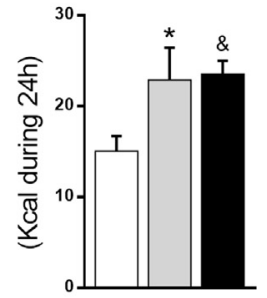

C. 24h Food Intake after Exercise

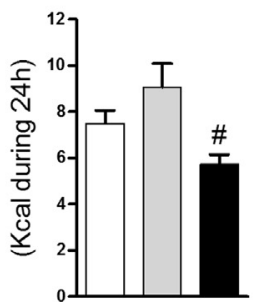

D.

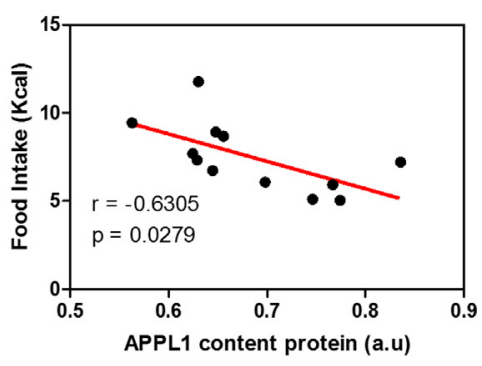

Fig. 6. (A) Experimental design of energy intake assessment. (B) One-day food intake before exercise $(24 \mathrm{~h})$ and (C) accumulated food intake after physical exercise $(n=5)$ were recorded. (D) Correlation between the levels of APPL1/ $\beta$-Actin and food intake $(n=14)$. (CTL $(n=4)$, HFD $(n=5)$, and HFD-EXE $(n=5)$. 
quite unclear, but it seems to be dependent on glucose levels. Suyama et al. [31] showed the ICV administration of both adiponectin and glucose increased food intake. Furthermore, the ICV administration of only adiponectin reduced food intake. From these findings, it is possible to conclude that adiponectin at low glucose levels depolarizes hypothalamic ARC proopiomelanocortin neurons, reducing food intake [31]. Similarly, Sun and colleagues [7] showed a synergic effect of adiponectin and leptin in vitro. Adiponectin stimulates the depolarization of POMC neurons of the arcuate nucleus and potentiates the leptin effect [7]. In contrast, adiponectin displayed an inhibitory effect in the NPY/AgRP neurons, balancing the energy homeostasis [7].

Neither study showed the APPL1 action in this context, but it is clear that APPL1 can regulate the Akt pathway [7,31]. Ding et al. showed that leptin stimulates APPL1, but silenced APPL1 reduced Akt phosphorylation stimulated by leptin in cancer cells [8]. These findings corroborate our results once the obesity decrease APPL1 content and Akt phosphorylation, while the physical exercise is able to increase APPL1 leptin-stimulated and Akt phosphorylation. Herein, the animals were submitted to physical exercise and, after $24 \mathrm{~h}$, exhibited a lower food intake than the sedentary obese animals, showing the effect of physical exercise in restoring food intake control in obesity conditions. Thus, our results suggest that physical exercise can control food intake via the APPL1/Akt pathway by leptin stimulation.

Coope and colleagues reported the presence of AdipoR1 and AdipoR2 in the hypothalamus of Wistar rats [2]. Intracerebroventricular adiponectin injection reduced food intake, which was accompanied by the activation/engagement of IRS1/2, ERK, Akt, Forkhead transcriptional factor class $\mathrm{O} 1$ (FoxO1), Janus kinase 2 (JAK2), and signal transducers and activators of transcription 3 (STAT3). All these actions were dependent on AdipoR1, since inhibition of this receptor, and not of AdipoR2, completely reversed the effects described above. On the order hand, another previous study [3] using rats as animal model indicated other central effects of adiponectin on spontaneous activity, showing that these central effects might depend on the species since in our study the analyses were performed with Swiss mice. Additionally, in our study, there was no difference in the hypothalamic content of APPL2, a protein with a counter-regulatory effect on the insulin pathway [32]. However, longer exposure studies of the animals to the high-fat diet are necessary to verify if the content of APPL2 in the hypothalamus changes.

In summary, our findings provided important evidence that an acute physical exercise session increased the hypothalamic APPL1 protein content in high-fat diet induced-obese mice. These findings expand the knowledge regarding the effect of physical exercise on the hypothalamic circuits involved in food intake control.

\section{Acknowledgments}

The authors thank AR Calixto, to Obesity and Comorbidities Research Center - OCRC, to FAPESP (2016/18488-8) and CNPq (306535/2017-3) to all support during the experiment.

\section{Author contributions}

R.C.G. was responsible for the experimental design, the data collection, tissue extraction and the manuscript writing. V.R.M. and G.P.F. were responsible for the images editing and glucose tolerance test. G.K.K. and S.C.B.R.N. were responsible for the manuscript writing. J.D.B., A.S.R.S., D.E.C, and L.P.M. were responsible for the data analysis and the manuscript review. J.R.P. and E.R.R. provided the laboratory support, discussed and reviewed the manuscript. All authors approve this submission and are in accordance with the journal guidelines.

\section{References}

[1] C.S. Morgen, T.I.A. Sørensen, Obesity: global trends in the prevalence of overweight and obesity, Nat. Rev. Endocrinol. 10 (2014) 513-514, http://dx.doi.org/10.1038/ nrendo.2014.124.

[2] A. Coope, M. Milanski, E.P. Araújo, M. Tambascia, M.J.A. Saad, B. Geloneze, L.A. Velloso, AdipoR1 mediates the anorexigenic and insulin/leptin-like actions of adiponectin in the hypothalamus, FEBS Lett. 582 (2008) 1471-1476, http://dx.doi. org /10.1016/j.febslet.2008.03.037.

[3] Y. Miyatake, T. Shiuchi, T. Ueta, Y. Taniguchi, A. Futami, F. Sato, T. Kitamura, R. Tsutsumi, N. Harada, Y. Nakaya, H. Sakaue, Intracerebroventricular injection of adiponectin regulates locomotor activity in rats, J. Med. Investig. 62 (2015) 199-203, http://dx.doi.org/10.2152/jmi.62.199.

[4] H. Ruan, L.Q. Dong, Adiponectin signaling and function in insulin target tissues, J. Mol. Cell Biol. 8 (2016) 101-109, http://dx.doi.org/10.1093/jmcb/mjw014.

[5] S.S. Deepa, L.Q. Dong, APPL1: role in adiponectin signaling and beyond, Am. J. Physiol. Endocrinol. Metab. 296 (2009) E22-E36, http://dx.doi.org/10.1152/ ajpendo.90731.2008.

[6] Z. Liu, T. Xiao, X. Peng, G. Li, F. Hu, APPLs: more than just adiponectin receptor binding proteins, Cell Signal 32 (2017) 76-84, http://dx.doi.org/10.1016/j.cellsig. 2017.01.018.

[7] J. Sun, Y. Gao, T. Yao, Y. Huang, Z. He, X. Kong, K. Jiang Yu, R. Tao Wang, H. Guo, J. Yan, Y. Chang, H. Chen, P.E. Scherer, T. Liu, K.W. Williams, Adiponectin potentiates the acute effects of leptin in arcuate Pomc neurons, Mol. Metab. 5 (2016) 882-891, http://dx.doi.org/10.1016/j.molmet.2016.08.007.

[8] Y. Ding, Y. Cao, B. Wang, L. Wang, Y. Zhang, D. Zhang, X. Chen, M. Li, C. Wang, APPL1-mediating leptin signaling contributes to proliferation and migration of cancer cells, PLoS One. 11 (2016) 1-14, http://dx.doi.org/10.1371/journal.pone. 0166172.

[9] Y. Benomar, H. Amine, D. Crépin, S. Al Rifai, L. Riffault, A. Gertler, M. Taouis, Central Resistin/TLR4 impairs adiponectin signaling, contributing to insulin and FGF21 resistance, Diabetes 65 (2016) 913-926, http://dx.doi.org/10.2337/db151029.

[10] A. Schenck, L. Goto-Silva, C. Collinet, M. Rhinn, A. Giner, B. Habermann, M. Brand, M. Zerial, The endosomal protein Appl1 mediates Akt substrate specificity and cell survival in vertebrate development, Cell 133 (2008) 486-497, http://dx.doi.org/ 10.1016/j.cell.2008.02.044.

[11] M.E. Cleasby, Q. Lau, E. Polkinghorne, S.A. Patel, S.J. Leslie, N. Turner, G.J. Cooney, A. Xu, E.W. Kraegen, The adaptor protein APPL1 increases glycogen accumulation in rat skeletal muscle through activation of the PI3-kinase signalling pathway, J. Endocrinol. 210 (2011) 81-92, http://dx.doi.org/10.1530/JOE-110039.

[12] K.K.Y. Cheng, M.A. Iglesias, K.S.L. Lam, Y. Wang, G. Sweeney, W. Zhu, P.M. Vanhoutte, E.W. Kraegen, A. Xu, APPL1 potentiates insulin-mediated inhibition of hepatic glucose production and alleviates diabetes via Akt activation in mice, Cell Metab. 9 (2009) 417-427, http://dx.doi.org/10.1016/j.cmet.2009.03. 013.

[13] J. Farias, R. Maggi, C. Tromm, L. Silva, T. Luciano, S. Marques, F. Lira, C. de Souza R. Pinho, Exercise training performed simultaneously to a high-fat diet reduces the degree of insulin resistance and improves adipoR1-2/APPL1 protein levels in mice, Lipids Health Dis. 11 (2012) 134, http://dx.doi.org/10.1186/1476-511x-11-134.

[14] M.P. Scheid, G. Sweeney, The role of adiponectin signaling in metabolic syndrome and cancer, Rev. Endocr. Metab. Disord. 15 (2014) 157-167, http://dx.doi.org/10. 1007/s11154-013-9265-5.

[15] G. Frühbeck, V. Catalán, A. Rodríguez, B. Ramírez, S. Becerril, P. Portincasa, J. Gómez-Ambrosi, Normalization of adiponectin concentrations by leptin replacement in ob/ob mice is accompanied by reductions in systemic oxidative stress and inflammation, Sci. Rep. 7 (2017) 2752, http://dx.doi.org/10.1038/s41598017-02848-0.

[16] C. Wang, X. Xin, R. Xiang, F.J. Ramos, M. Liu, H.J. Lee, H. Chen, X. Mao, C.K. Kikani, F. Liu, L.Q. Dong, Yin-Yang regulation of adiponectin signaling by APPL isoforms in muscle cells, J. Biol. Chem. 284 (2009) 31608-31615, http://dx. doi.org/10.1074/jbc.M109.010355.

[17] S. Jiang, Q. Fang, W. Yu, R. Zhang, C. Hu, K. Dong, Y. Bao, C. Wang, K. Xiang, W. Jia, Genetic variations in APPL2 are associated with overweight and obesity in a Chinese population with normal glucose tolerance, BMC Med. Genet. 13 (2012) 22, http://dx.doi.org/10.1186/1471-2350-13-22.

[18] E.R. Ropelle, M.B. Flores, D.E. Cintra, G.Z. Rocha, J.R. Pauli, J. Morari, C.T. de Souza, J.C. Moraes, P.O. Prada, D. Guadagnini, R.M. Marin, A.G. Oliveira, T.M. Augusto, H.F. Carvalho, L.A. Velloso, M.J.A. Saad, J.B.C. Carvalheira, IL-6 and IL-10 anti-inflammatory activity links exercise to hypothalamic insulin and leptin sensitivity through IKK $\beta$ and ER stress inhibition, PLoS Biol. 8 (2010) 31-32, http://dx.doi.org/10.1371/journal.pbio.1000465.

[19] R. Marinho, E.R. Ropelle, D.E. Cintra, C.T. De Souza, A.S.R. Da Silva, F.C. Bertoli, E. Colantonio, V. D'Almeida, J.R. Pauli, Endurance exercise training increases APPL1 expression and improves insulin signaling in the hepatic tissue of diet-induced obese mice, independently of weight loss, J. Cell Physiol. 227 (2012) 2917-2926, http://dx.doi.org/10.1002/jcp.23037.

[20] D.E. Cintra, E.R. Ropelle, J.C. Moraes, J.R. Pauli, J. Morari, C.T. de Souza, R. Grimaldi, M. Stahl, J.B. Carvalheira, M.J. Saad, L.A. Velloso, Unsaturated fatty acids revert diet-induced hypothalamic inflammation in obesity, PLoS One 7 (2012), http://dx.doi.org/10.1371/journal.pone.0030571.

[21] J.R. Pauli, E.R. Ropelle, D.E. Cintra, M.A. Carvalho-Filho, J.C. Moraes, C.T. De Souza, L.A. Velloso, J.B.C. Carvalheira, M.J.A. Saad, Acute physical exercise reverses S-nitrosation of the insulin receptor, insulin receptor substrate 1 and protein kinase B/Akt in diet-induced obese Wistar rats, J. Physiol. 586 (2008) 659-671, http://dx.doi.org/10.1113/jphysiol.2007.142414.

[22] J.C.B. Ferreira, N.P.L. Rolim, J.B. Bartholomeu, C.A. Gobatto, E. Kokubun, P.C. Brum, Maximal lactate steady state in running mice: effect of exercise training, 
Clin. Exp. Pharmacol. Physiol. 34 (2007) 760-765, http://dx.doi.org/10.1111/j. 1440-1681.2007.04635.x.

[23] C.M. Patterson, S.G. Bouret, A.A. Dunn-Meynell, B.E. Levin, Three weeks of postweaning exercise in DIO rats produces prolonged increases in central leptin sensitivity and signaling, AJP Regul. Integr. Comp. Physiol. 296 (2008) R537-R548, http://dx.doi.org/10.1152/ajpregu.90859.2008.

[24] V.R. Muñoz, R.C. Gaspar, B.M. Crisol, G.P. Formigari, M.R. Sant'Ana, J.D. Botezelli, R.S. Gaspar, A.S.R. da Silva, D.E. Cintra, L.P. de Moura, E.R. Ropelle, J.R. Pauli, Physical exercise reduces pyruvate carboxylase (PCB) and contributes to hyperglycemia reduction in obese mice, J. Physiol. Sci. (2017), http://dx.doi.org/10. 1007/s12576-017-0559-3.

[25] U.K. Laemmli, Cleavage of structural proteins during the assembly of the head of bacteriophage T4, Nature 227 (1970) 680-685, http://dx.doi.org/10.1038/ $227680 \mathrm{a} 0$.

[26] R. Marinho, R.A. Mekary, V.R. Muñoz, R.J. Gomes, J.R. Pauli, L.P. de Moura, Regulation of hepatic TRB3/Akt interaction induced by physical exercise and its effect on the hepatic glucose production in an insulin resistance state, Diabetol. Metab. Syndr. 7 (2015) 67, http://dx.doi.org/10.1186/s13098-015-0064-x.

[27] Y. Benomar, A. Gertler, P. De Lacy, D. Crépin, H.O. Hamouda, L. Riffault, M. Taouis, Central resistin overexposure induces insulin resistance through toll-like receptor 4, Diabetes 62 (2013) 102-144, http://dx.doi.org/10.2337/db12-0237.
[28] N.S. Singhal, M.A. Lazar, R.S. Ahima, Central resistin induces hepatic insulin resistance via neuropeptide Y, J. Neurosci. 27 (2007) 12924-12932, http://dx.doi org/10.1523/JNEUROSCI.2443-07.2007.

[29] S. Tovar, R. Nogueiras, L.Y.C. Tung, T.R. Castañeda, M.J. Vázquez, A. Morris, L.M. Williams, S.L. Dickson, C. Diéguez, Central administration of resistin promotes short-term satiety in rats, Eur. J. Endocrinol. 153 (2005), http://dx.doi.org/10. 1530/eje.1.01999.

[30] B.D.A. Rodrigues, L.S.S. Pauli, C.T. de Souza, A.S.R. da Silva, D.E.C. Cintra, R. Marinho, L.P. de Moura, E.C.C. Ropelle, J.D. Botezelli, E.R. Ropelle, J.R. Pauli, Acute exercise decreases tribbles homolog 3 protein levels in the hypothalamus of obese rats, Med. Sci. Sport. Exerc. 47 (2015) 1613-1623, http://dx.doi.org/10. 1249/MSS.0000000000000585.

[31] S. Suyama, F. Maekawa, Y. Maejima, N. Kubota, T. Kadowaki, T. Yada, Glucose level determines excitatory or inhibitory effects of adiponectin on arcuate POMC neuron activity and feeding, Sci. Rep. 6 (2016) 30796, http://dx.doi.org/10.1038/ srep30796.

[32] K.K.Y. Cheng, W. Zhu, B. Chen, Y. Wang, D. Wu, G. Sweeney, B. Wang, K.S.L. Lam, A. Xu, The adaptor protein APPL2 inhibits insulin-stimulated glucose uptake by interacting with TBC1D1 in skeletal muscle, Diabetes 63 (2014) 3748-3758, http:// dx.doi.org/10.2337/db14-0337. 